\title{
Acidosis with hyperuricemia and renal tubular damage in viral gastroenteritis
}

\author{
Taku Morita $•$ Mikiya Fujieda
}

Received: 12 July 2011 /Accepted: 24 August 2011 / Published online: 16 September 2011

(C) The Author(s) 2011. This article is published with open access at Springerlink.com

Sir,

We read with interest the article entitled "Cause of uric acid stones in rotavirus-associated gastroenteritis" by Kaneko et al., which was recently published in Pediatric Nephrology [1]. We encountered four cases of postrenal renal failure induced by ammonium acid urate (AAU) stones associated with rotavirus gastroenteritis in patients without metabolic disorder, drug administration, abnormality of the urinary tract, urinary tract infection, or mutation of the human urate transporter 1 (hURAT1) associated with SLC22A12. Ashida et al. described a case with postrenal renal failure caused by an AAU stone associated with norovirus gastroenteritis [2], but most case reports of this condition have been associated with rotavirus infection. To examine these issues, we compared clinical and laboratory data in patients with rotavirus and norovirus gastroenteritis.

Participants in our study were patients with rotavirus or norovirus gastroenteritis who were admitted for treatment of diarrhea and vomiting with dehydration between January 2006 and March 2009. These patients included 42 with rotavirus infection (Group R; mean age, 1.7 years; range, $0.3-$ 2.0 years; 32 boys, 10 girls) and 23 with norovirus infection (Group N; mean age, 1.7 years; range, $0.5-2.5$ years; 14 boys, 9 girls). None of the patients had any bacterial infection or underlying disease such as metabolic disorder, and none developed postrenal renal failure. RT-PCR was used to detect rotavirus or norovirus genome in stools. Age, sex, and results from blood chemistry tests, blood gas tests (venous), and urinalysis were compared between groups. The two-sample $t$

T. Morita $\cdot$ M. Fujieda $(\bowtie)$

Department of Pediatrics, Kochi Medical School,

Kochi University,

Kohasu, Oko-cho, Nankoku,

Kochi 783-8505, Japan

e-mail: fujiedam@kochi-u.ac.jp test, Mann-Whitney test, and Fisher's exact test were used for comparisons between groups. Values of $p<0.05$ were considered statistically significant.

Age, male-to-female ratio, and days from onset to admission did not differ between the groups. Degree of dehydration and duration of fever and hospitalization were similar in the two groups (data not shown), but temperature on admission was significantly higher $(p=0.04)$ in Group R. No differences in creatinine ( $\mathrm{Crn}$ ) or blood urea nitrogen (BUN) levels were seen between groups. $\mathrm{HCO}_{3}^{-}$level in blood tended to be lower, venous gas $\mathrm{pH}$ (Group R: mean, 7.360; range, 7.268-7.442, Group N: mean, 7.410; range, 7.2837.432 ) was significantly lower ( $p=0.03$ ), and concentrations of uric acid (UA) in blood (Group R: mean, $440 \mu \mathrm{mol} / \mathrm{l}$; range,184-708 $\mu \mathrm{mol} / \mathrm{l}$, Group N: mean, $363 \mu \mathrm{mol} / \mathrm{l}$; range, 184-630 $\mu \mathrm{mol} / \mathrm{l}$ ), and frequency of UA $>595 \mu \mathrm{mol} / \mathrm{l}$ (Group R: $31.0 \%$, Group N $0 \%$ ) were significantly higher in Group $\mathrm{R}(p=0.04, p=0.01$ respectively).

Urinary $\mathrm{pH}$ was lower and urinary excretion of UA (UA/ $\mathrm{Crn}), \beta_{2}$-microglobulin $\left(\beta_{2} \mathrm{MG}\right)$ and $\mathrm{N}$-acetyl- $\beta$-glucosaminidase (NAG) were higher in Group R. Urinary UA/Crn $>1.2$ was found in 13 out of 20 patients in Group R, compared with 3 out of 11 patients in Group N $(p=0.04)$. Excretion of $\beta_{2} \mathrm{MG}>500 \mu \mathrm{g} / \mathrm{l}$ occurred in 12 out of 20 patients (mean, $2,004 \mu \mathrm{g} / 1$; range, $638-3,383 \mu \mathrm{g} / \mathrm{l})$ in Group R and only 1 out of 9 patients $(906 \mu \mathrm{g} / \mathrm{l})$ in Group N $(p=0.02)$. Urinary excretion of NAG $>10 \mathrm{U} / 1$ occurred in 8 out of 25 patients (mean, 29.0 U/1; range, 13.3-75.0 U/l) in Group R and only 1 out of 9 patients $(16.3 \mathrm{U} / \mathrm{l})$ in Group N. Blood levels of $\beta_{2} \mathrm{MG}$ were similar in the two groups (data not shown).

Viral gastroenteritis induces frequent diarrhea and loss of bicarbonate by small intestinal epithelial cells. This damage results in metabolic acidosis and a subsequent increase in urinary ammonium excretion in response to the acidosis. The combination of aciduria, hyperuricemia, and hyperammonuria 
can induce formation of AAU stones and crystals. Severe and persistent acidosis induced by rotavirus or norovirus infection may thus cause postrenal renal failure due to AAU stones.

Our data showed that patients with rotavirus gastroenteritis experience high fever, high levels of hyperuricemia and acidosis, and a tendency toward high levels of urinary excretion of UA, $\beta_{2} \mathrm{MG}$, and NAG, compared with patients with norovirus gastroenteritis. These findings suggest that tissue damage caused by rotavirus is more severe than that caused by norovirus, and that rotavirus might be toxic to both tubular epithelial cells and small intestinal epithelial cells. Urinary $\mathrm{pH}$ and blood bicarbonate levels did not differ significantly between groups, possibly because most patients received intravenous fluids before admission. We recently detected rotavirus in urinary sediment cells of patients with rotavirus gastroenteritis [3], suggesting that rotavirus may attack tubular epithelial cells directly.

Acidosis, hyperuricemia, and urine output after hydration should be considered in patients with viral gastroenteritis for prevention of postrenal renal failure due to AAU stones or crystals. However, many children with rotavirus or norovirus infection are treated annually, and only a small proportion of patients develop stones. A large-scale study and worldwide survey are required to clarify risk factors for the formation of AAU stones, and to determine whether viral gastroenteritis caused by rotavirus or norovirus plays any significant role in the formation of AAU stones that result in postrenal renal failure.

Open Access This article is distributed under the terms of the Creative Commons Attribution Noncommercial License which permits any noncommercial use, distribution, and reproduction in any medium, provided the original author(s) and source are credited.

\section{References}

1. Kaneko K, Shimo T, Hirabayashi M, Ito T, Okazaki H, Harada Y (2010) Cause of uric acid stones in rotavirus-associated gastroenteritis. Pediatr Nephrol 25:2187-2188

2. Ashida A, Shirasu A, Nakakura H, Tamai H (2010) Acute renal failure due to obstructive urate stones associated with norovirus gastroenteritis. Pediatr Nephrol 25:2377-2378

3. Yokoyama T, Sugimoto N, Taniguchi K, Komoto S, Yuno T, Ohta K, Hashimoto H, Seno A, Ashida A, Fujieda M, Nishio S, Ueno K, Shimizu M, Yachie A (2011) Molecular and immunohistochemical detection of rotavirus in urinary sediment cells of children with rotavirus gastroenteritis. Clin Microbiol Infect 17:1190-1193 